\title{
Preparation of a boron nitride single layer on a polycrystalline Rh surface
}

\author{
János Kiss $^{\text {a,b,* }}$, Károly Révész ${ }^{\text {a,b }}$, Gábor Klivényi ${ }^{\text {a,b }}$, Frigyes Solymosi ${ }^{\text {a,b }}$ \\ a Department of Physical Chemistry and Materials Science, University of Szeged, Aradi vértanúk t. 1, H-6720 Szeged, Hungary \\ ${ }^{\mathrm{b}}$ Reaction Kinetics and Surface Chemistry, Research Group of Hungarian Academy of Sciences, Rerrich B. t. 1, H-6720 Szeged, Hungary
}

\section{A R T I C L E I N F O}

\section{Article history:}

Received 30 July 2012

Received in revised form 26 October 2012

Accepted 28 October 2012

Available online 3 November 2012

\section{Keywords:}

Segregation of boron

NO dissociation on Rh

Formation of $\mathrm{B}-\mathrm{N}$ bond

Boron nitride

Auger fine structures

\begin{abstract}
A B S T R A C T
The segregation of boron and its reactivity toward nitric oxide have been investigated by means of highresolution Auger spectroscopy (AES), X-ray photoelectron spectroscopy (XPS), ultraviolet photoelectron spectroscopy (UPS), and thermal desorption spectroscopy (TDS). The segregation of boron from a Rh foil started from $700 \mathrm{~K}$. Its presence altered the surface behaviors of Rh; the uptake of NO increased by about $30-37 \%$. Whereas the dissociation of NO was about $3-10 \%$ on a clean, boron-free surface, the extent of dissociation (at saturation) at highest boron level was almost $98 \%$. This feature strongly suggest a direct interaction between $\mathrm{NO}$ and boron on the surface. The presence of boron greatly stabilized the adsorbed nitrogen and oxygen formed in NO dissociation. Boron oxide $\left(\mathrm{BO}, \mathrm{B}_{2} \mathrm{O}_{2}\right)$ sublimated from the surface below $1000 \mathrm{~K}$. Clean, single BN layer formed on the surface close to a monolayer regime, presumable in nanomash structure.
\end{abstract}

(C) 2012 Elsevier B.V. All rights reserved.

\section{Introduction}

Graphene nanoribbons, atomically thin strips of graphene that are just a few nanometers wide, are considered to be excellent candidates for future electronics application as their properties can be adjusted through width and edge shape [1,3]. Hexagonal boron nitride (h-BN) has great potential for use as the dielectric layer in functional heterostructured devices, which exploit the remarkable properties of graphene [1,2]. The combination of graphene and h$\mathrm{BN}$ opens up the existing possibility of creating a new class of atomically thin multilayered heterostructures. Graphene and h-BN share the same crystal structure and have very similar lattice constant but, unlike graphene, h-BN is an insulator with a large band gap [4]. Along graphene, boron nitride nanoribbons have attracted more and more fundamental research interest. For instance, researchers have found that magnetism could be induced in such ribbons by replacement of $\mathrm{B}$ or $\mathrm{N}$ with $\mathrm{Be}, \mathrm{C}, \mathrm{Al}, \mathrm{Si}$, or with vacancy defects. They also found that the ribbons could have a narrowed band gap and improved electrical conductivity tuned by a transverse electric field or special edge structure. These finding promise a bright future in optoelectronics and spintronics for atomically thin boron nitride nanoribbons. However, a major challenge in providing experimental evidence is that the preparation of atomically thin boron nitride is very difficult [5-7]. Since first applications of BN in fundamental research that the interest in single layer boron nitride $(\mathrm{sBN})$ has

\footnotetext{
* Corresponding author at: Department of Physical Chemistry and Materials Science, University of Szeged, Hungary. Tel.: +36 62 544803; fax: +36 62546482.

E-mail address: jkiss@chem.u-szeged.hu (J. Kiss).
}

been increasing steadily. In the past several experimental studies have been performed including TEM [8-10], AFM [11] and optical and Raman spectroscopy [9] for characterization of the material's surface. The main experimental approaches for producing sBN have been both mechanical [9,11] and chemical [10] exfoliation.

One of the surface science tools producing boron source is the dehydrogenation of decaborane on metal surfaces [12]. Hexagonal boron nitride (h-BN) was prepared by thermal decomposition of borazine, $\mathrm{B}_{3} \mathrm{H}_{6} \mathrm{~N}_{3}$ on $\mathrm{Ni}(1111)$ [13], $\mathrm{Cu}(1111)$ [14] and $\mathrm{Rh}(1111)$ [15]. Surface boron can be prepared by segregation process, too. Boron segregates from the bulk to the surface by annealing the polycrystalline Rh surface at 750-1200 K [16,17]. We earlier demonstrated that boron impurity segregating to an Rh surface dramatically alters the reactivity of the Rh surface toward $\mathrm{N}$ - and O-containing moieties, such as $(\mathrm{CN})_{2}$ [18], $\mathrm{H}_{2} \mathrm{O}$ [17], $\mathrm{CO}_{2}[19,20]$. A possible reason for this phenomenon is that boron forms very strong bonds with $\mathrm{N}$ and $\mathrm{O}$, which can promote the processes of surface dissociation of the adsorbed molecules. Following surface dissociation, we detected the formation of dissociation products via thermal desorption, and a new feature at 9.4 and $7.4 \mathrm{eV}$ in the electron energy loss spectrum due to $\mathrm{B}-\mathrm{O}$ and $\mathrm{B}-\mathrm{N}$ bond, respectively. The segregation of boron onto a Rh surface has also been observed by other authors [21-23].

In present work we examine the segregation of boron and interaction of segregated boron with NO by means of different electron spectroscopic methods, such as high resolution AES, XPS, UPS and thermal desorption mass spectrometry (TDS). The primary aims were to determine the monolayer $\mathrm{BN}$ formed during the reaction between the dissociation product and segregated boron. Earlier the interaction of NO with clean Rh(1 11 ) surface was investigated widely by different surface science techniques [24-31]. The initial 
adsorption of NO on clean Rh surface is dissociative at $300 \mathrm{~K}$. At higher NO coverage the adsorption is molecular.

\section{Experimental}

The experiments were performed in an ultra-high vacuum system, with a background pressure in the low-to middle $10^{-10} \mathrm{mbar}$ range, produced by turbo molecular and titanium getter pumps. The system was equipped with a hemispherical analyser (LeyboldHeraeus LHS-10) for UPS, XPS and high resolution AES, an Ar ion gun for cleaning and a quadrupole mass spectrometer for TDS.

UPS was performed by using $\mathrm{He} \mathrm{I}(21.22 \mathrm{eV})$ and $\mathrm{He}$ II $(40.81 \mathrm{eV})$ radiation. The angles between the surface normal and the UV lamp and between the surface normal and the analyser were $75^{\circ}$ and $16^{\circ}$, respectively. The photoelectrons were excited by Al K $\alpha$ radiation $(1486.7 \mathrm{eV})$ in the XPS regime. The energies of the XPS peaks were calibrated relative to the Fermi level of $R h$, metallic $R h 3 d_{3 / 2}$ is positioned at $307.1 \mathrm{eV}$. The photoemissions were measured by using a pass energy of $50 \mathrm{eV}$ in order to get the optimum resolution by maintaining an acceptable signal-to-noise ratio at measuring time of $60 \mathrm{~min}$. High resolution Auger electron spectra were taken in $d N(E) / d E$ mode using a lock-in amplifier (Ithacho, Dinatrac 391 A) with $0.5-2 \mathrm{eV}$ peak-to-peak modulation. At these parameters the estimated resolution was $1.6-1.9 \mathrm{eV}$. In order to minimize the electron-induced changes in our experiments, we used $0.2-1 \mu \mathrm{A}$ of incident current and $2.5 \mathrm{kV}$ of incident energy.

The polycrystalline $\mathrm{Rh}$ foil $(10 \mathrm{~mm} \times 10 \mathrm{~mm}$ and $0.127 \mathrm{~mm}$ thick $99.9 \%$ purity) was purchased from Hicol Co. The initial cleaning procedure has been described previously $[19,20]$. It is consisted of ion bombardment and annealing at $1270 \mathrm{~K}$. The major contaminants of Rh foil were B, P, S, and C. The P, C and S were easily removed, but no complete elimination of boron was achieved even after several cleaning cycles. The final thermal treatment was performed at $700 \mathrm{~K}$.

Segregation of boron was achieved by annealing the $\mathrm{Rh}$ foil at $750-1270 \mathrm{~K}$. The level of surface boron is characterized by the relative intensity of the boron Auger signal, $R_{B}=\mathrm{B}_{178} / \mathrm{Rh}_{302} . \mathrm{B}_{178}$ and $\mathrm{Rh}_{302}$ represent peak-to-peak intensity ratios of boron KLL and rhodium MNN Auger transitions determined in differentiated mode. The peak positions are taken from the negative going of the spectra.

\section{Results and discussion}

\subsection{General features of segregated boron on rhodium surfaces}

The segregation of boron was pointed out in earlier works [17-24,32]. It has been observed that boron is a major bulk impurity $(17 \mathrm{ppm})$ in $\mathrm{Rh}$. When the surface is heated the boron segregates to the surface. Fig. 1 shows a typical segregation curve, $R_{B}$ values (relative intensity of boron Auger signal) are plotted against temperature. When the freshly sputtered surface was heated above $700 \mathrm{~K}$ boron signal showed up, it reached a maximum value at $1000 \mathrm{~K}$. (Experiments cannot be extended to higher temperatures because of the construction of our sample holder.) Boron coverages were calculated roughly by using the ratio of the theoretical XPS photoionization cross-section [33] for adsorbed boron and oxygen and comparing to the XPS signal from the known oxygen coverage on polycrystalline $\mathrm{Rh}$ at saturation $\left(5.8 \times 10^{14} \mathrm{O}\right.$ atoms $\left./ \mathrm{cm}^{2}\right)$ [34]. In this way we found $7.96 \times 10^{14} \mathrm{~B}$ atoms $/ \mathrm{cm}^{2}$ at highest boron concentration, which about half of a monolayer. This value corresponds to a relative Auger peak ratio of $R_{B}=0.103$. Using the Langmuir-McLean equation, assuming that the segregation process is in equilibrium, the segregation energy is $-71.5 \mathrm{~kJ} / \mathrm{mol}$.

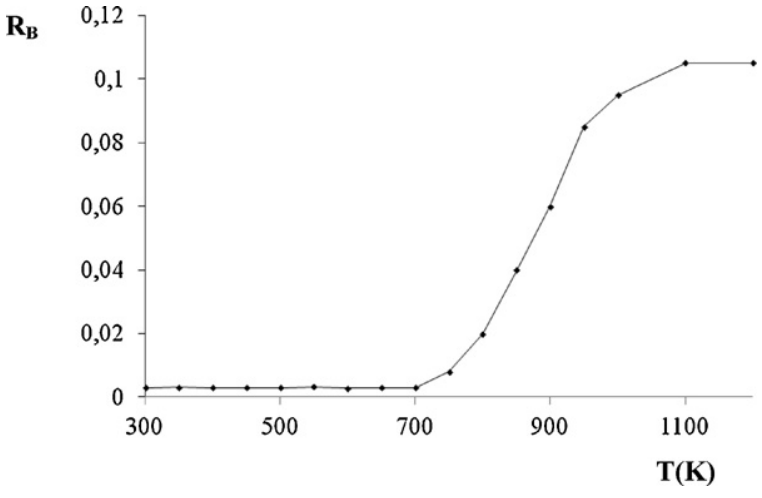

Fig. 1. Plot of the $\mathrm{B} / \mathrm{Rh}$ Auger peak ratio $\left(R_{B}\right)$ versus temperature.

The segregation exhibits significant space specificity. On the $\mathrm{Rh}(100)$ face, the segregated boron forms a $(3 \times 1)$ LEED pattern and as boron is depleted from the bulk, it then segregates to a lesser extent and forms a $(3 \times 3)$ ordered overlayer [23]. The segregation on the (755) face is many times larger than that on the $\operatorname{Rh}(331)$ face [21].

An analysis of the width of the He I UPS upon segregation of boron did not reveal any changes in the work function, indicating that the dipole moment produced by surface boron is very small. This is consistent with the similar Pauling electronegativities of B (2.0) and Rh (2.2), which suggest that charge transfer between these elements is minimal. Independently of the coverage, the $\mathrm{B}$ 1s level appeared at $187.8 \mathrm{eV}$ in XPS (Fig. 2). The peak exhibited $3.5 \mathrm{eV}$ FWHM at saturation. This value significantly larger than that observed for B $1 \mathrm{~s}$ on $\mathrm{Mo}(100)$ surface after adsorption of diborane [35]. We assume that the $B$ 1s photoemission signal is composed of

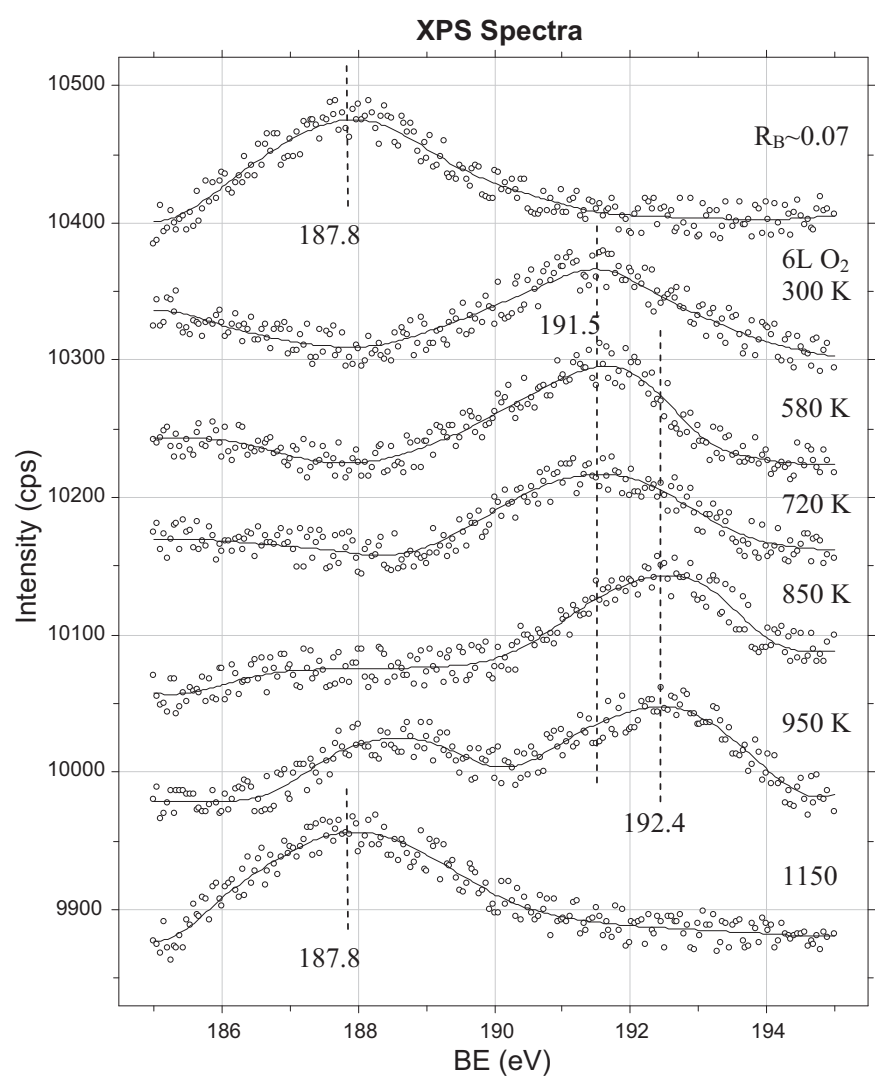

Fig. 2. XP spectra for $\mathrm{B} 1 \mathrm{~s}$ level after heating the sample $\left(R_{B} \approx 0.075\right)$ exposed to $6 \mathrm{~L}$ $\mathrm{O}_{2}$ at $300 \mathrm{~K}$ to different temperatures. 

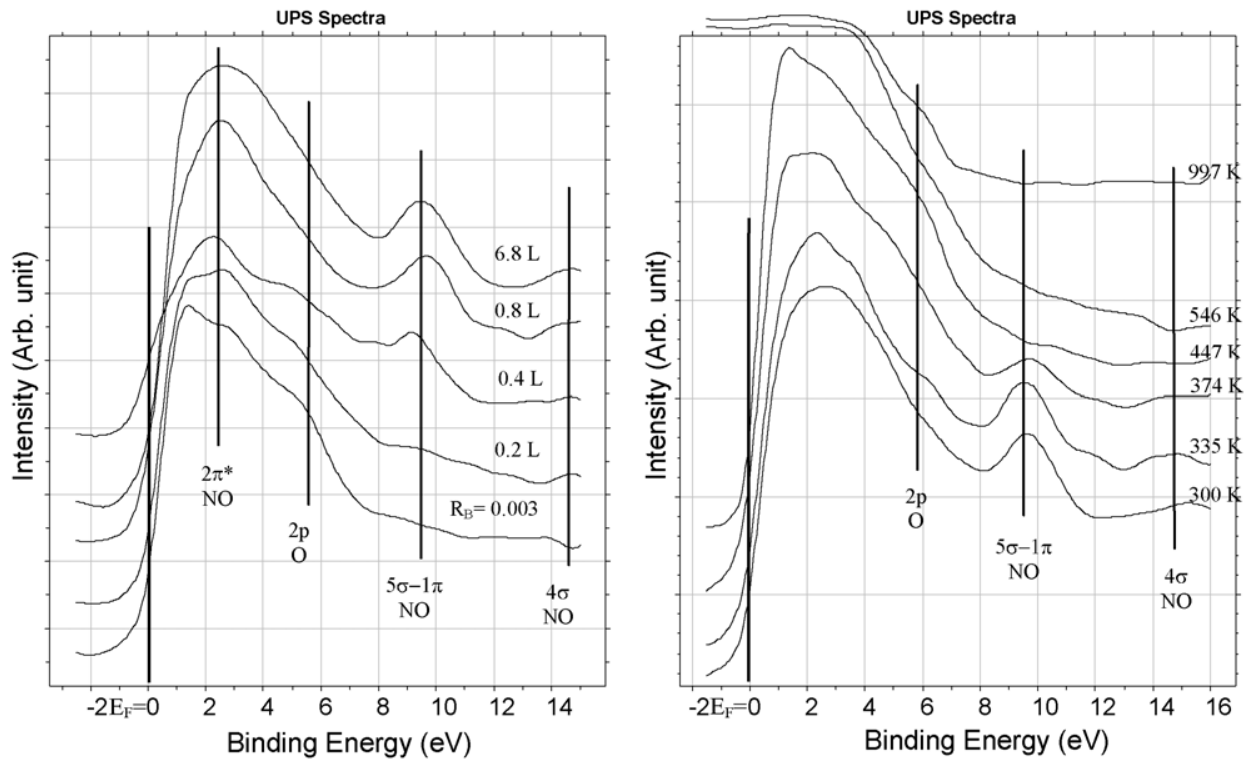

Fig. 3. UP spectra of adsorbed NO on clean surface at different exposures at $300 \mathrm{~K}$ and at different temperatures.

two or more overlapping peaks, indicating dimers or the formation of islands.

The segregation of boron on $\mathrm{Rh}$ foil produced a photoemission peak at $8.6 \mathrm{eV}$ in difference UPS spectra (not shown). The B 2p level would be expected at around $4.0-5.0 \mathrm{eV}$. The detection of this peak is doubtful, presumable due to its very low cross-section. The intensity of this photoemission at $8.6 \mathrm{eV}$ increased and it shifted slightly to higher binding energy with increasing of the surface concentration of boron [32]. In a UPS study on iron borides, peak due to emission from the boron $2 \mathrm{p}, 2 \mathrm{sp}^{2}$ and $2 \mathrm{~s}$ states were identified [36]. The B $2 \mathrm{sp}^{2}$ level is located at $7.0 \mathrm{eV}$ for $\mathrm{Fe}_{2} \mathrm{~B}$ and at $10.0 \mathrm{eV}$ for $\mathrm{FeB}$. According to the study by Joyner and Willis [36], the $2 \mathrm{sp}^{2}$ emission is due to a B-B interaction. As the intensity of the UPS peak at 8.6-9.0 eV increased with boron level on $\mathrm{Rh}$, we may assume that B-B interaction also exist in our case, too. Stair et al. [35,37] reached a similar conclusion for the $\mathrm{B} / \mathrm{Mo}\left(\begin{array}{lll}1 & 0 & 0\end{array}\right)$ system.

\subsection{Adsorption and decomposition of $N O$ on boron containing $R h$}

The chemical nature of adsorbed NO on boron-free polycrystalline $\mathrm{Rh}$ was almost identical to $\mathrm{Rh}(111)$ [30,38-41]. The appearance of the $02 \mathrm{p}$ UPS signal at $5.6-5.8 \mathrm{eV}$ indicates the dissociation of $\mathrm{NO}$ at low coverage at $300 \mathrm{~K}$. At higher exposures the adsorption is preferentially molecular. New photoemissions were produced at $\sim 2.3,9.3$ and $14.5 \mathrm{eV}$ below Fermi level (Fig. 3). The NO-induced emissions can be attributed to the $2 \pi^{*}, 1 \pi / 5 \sigma$ and $4 \sigma$ molecular levels, respectively. When the NO-saturated surface was heated, the intensities of the peaks at 9.3 and $14.5 \mathrm{eV}$ decreased above $354 \mathrm{~K}$ and these peaks disappeared at 400-432 K (Fig. 3). The emission at 5.6-5.8 eV was more stable; it was detected up to $997 \mathrm{~K}$. This emission can be attributed very probably to the formation of $\mathrm{B}-\mathrm{O}$ species at high temperatures where the segregation of boron is dominating. Molecular NO desorbs between 350 and $420 \mathrm{~K}$ with $T_{p}=381 \mathrm{~K}$. Nitrogen desorbs in three stages $\left(T_{p}=410\right.$, 550 and $640 \mathrm{~K}$ ). Some characteristic data for desorption are collected in Table 1. The results obtained suggest that the dissociation of NO is limited. The extent of dissociation is somewhat higher than on $\mathrm{Rh}(111)$ due to the higher number of defect sites. The calculations of DeLouise and Winograd [29], based on XPS measurements, showed that only $3 \%$ of the saturated layer dissociates at $300 \mathrm{~K}$ on single crystal of Rh. It should be also taken into account that the dissociation of NO in the saturated layer is hampered, as it requires free adsorption centers in the vicinity of molecularly adsorbed NO.

The presence of boron altered the surface behavior of Rh; the uptake of NO on boron containing surface increased by about $30-37 \%$. The extent of dissociation (at saturation) also increased; at higher boron impurity level it was almost 98\%. The peak temperatures for desorption of molecularly adsorbed NO from boron containing Rh were unaltered suggesting that this NO adsorbs and desorbs from Rh sites not influenced by boron adatoms (Table 1). However, the presence of boron greatly stabilized the adsorbed nitrogen and oxygen. This stabilizing effect was so great that the nitrogen formed in the boron promoted dissociation of NO did not desorb below $1200 \mathrm{~K}$. This feature strongly suggests a direct interaction between $\mathrm{N}$ and boron on the surface.

Fig. 4 shows the UPS spectra of $\mathrm{NO}$ as a function of NO exposure and the thermally treated NO covered surfaced on boroncontaminated surfaces. At low coverages, molecularly adsorbed NO was not detected; strong UP signal was obtained at 5.2-5.5 eV due to the adsorbed oxygen from NO dissociation (Fig. 4). At higher coverages (from $0.4 \mathrm{~L}$ ) a photoemissions due to $1 \pi / 5 \sigma$ orbitals of adsorbed NO molecule were detected. During heating the NO covered surface (Fig. 5) the emissions for molecular orbital of NO disappeared from $374 \mathrm{~K}$, the $\mathrm{O} 2 \mathrm{p}$ intensified, and a new photoemission appeared from $546 \mathrm{~K}$ at $9.0-9.5 \mathrm{eV}$. It could not be eliminated up to $1270 \mathrm{~K}$. This photoemission can be attributed to the formation of $\sigma$ bond between $\mathrm{B}$ and $\mathrm{N}$ [42].

In the next steps we followed the surface chemical changes during adsorption and thermal treatment by high resolution Auger electron spectroscopy. In certain cases due to the loss features originated from different electron-induced interband, intraband

Table 1

Characteristic data of desorption of NO from clean and boron containing Rh surfaces $\left(R_{B} \approx 0.075\right)$.

\begin{tabular}{llllc}
\hline Surface & Products & $T_{p}(\mathrm{~K})$ & Kinetics order & $E_{d}(\mathrm{~kJ} / \mathrm{mol})$ \\
\hline & $\mathrm{NO} / \mathrm{NO}$ & 381 & 1 & 111 \\
Clean & $\mathrm{N}_{2}\left(\beta_{1}\right) / \mathrm{NO}$ & 410 & 1 & 120 \\
& $\mathrm{~N}_{2}\left(\beta_{2}\right) / \mathrm{NO}$ & 550 & 1 & 160 \\
& $\mathrm{~N}_{2}\left(\beta_{3}\right) / \mathrm{NO}$ & 640 & 2 & - \\
& $\mathrm{NO} / \mathrm{NO}$ & 381 & 1 & 111 \\
Boron containing & $\mathrm{N}_{2}\left(\beta_{1}\right) / \mathrm{NO}$ & 402 & 1 & 117 \\
$R_{B} \approx 0.103$ & $\mathrm{~N}_{2}\left(\beta_{2}\right) / \mathrm{NO}$ & 580 & 2 & - \\
\hline
\end{tabular}




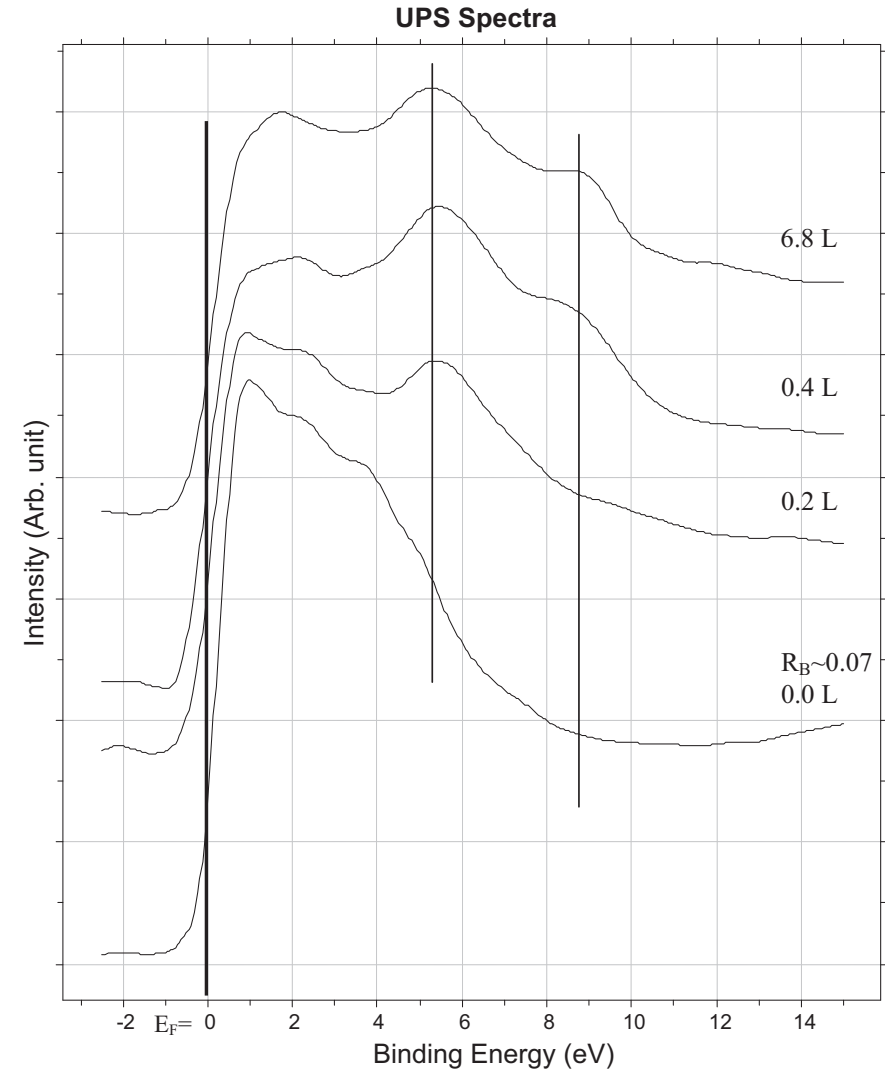

Fig. 4. UP spectra of adsorbed NO on boron containing Rh surfaces at different NO exposures at $300 \mathrm{~K}$.

transitions and plasmon losses, the Auger spectroscopy could be very sensitive to the chemical nature of adsorbed molecules. Fig. $6 \mathrm{~A}$ shows the oxygen AES signals with increasing NO exposures at highest boron concentration. At lowest NO coverage two AES

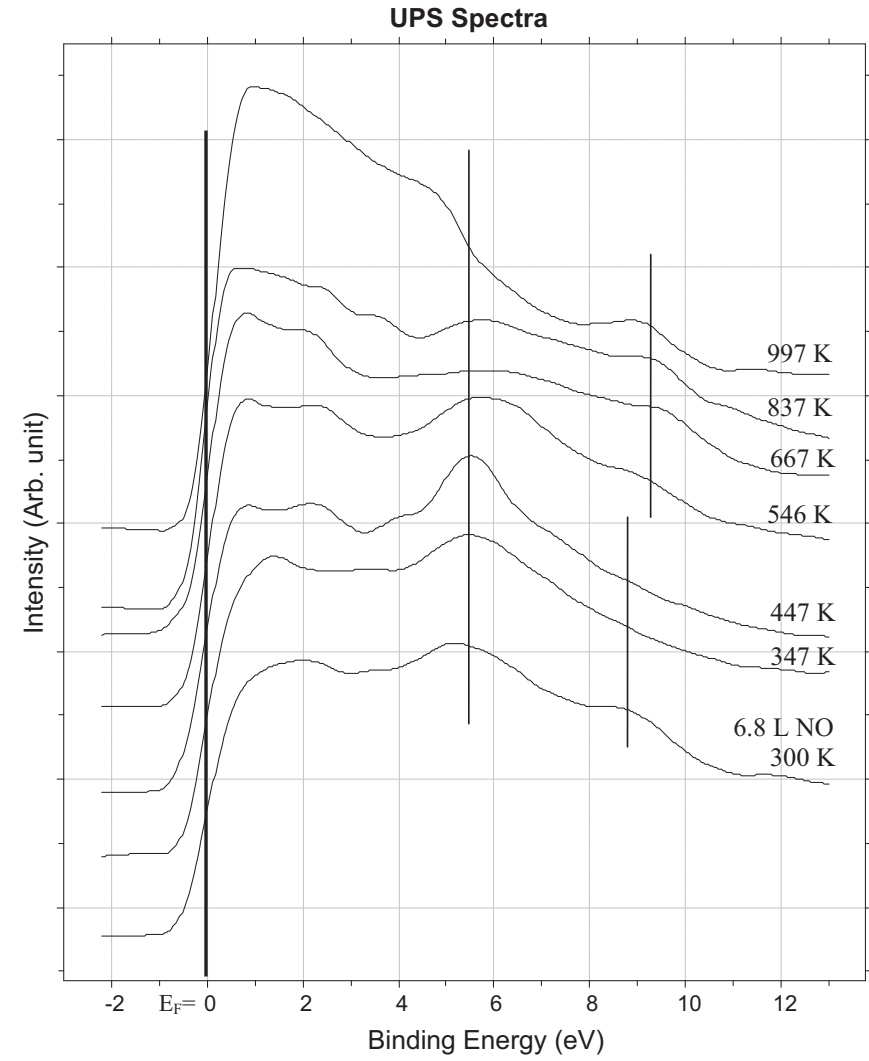

Fig. 5. UP spectra of NO saturated boron containing Rh surfaces at different temperatures.

transitions were detected at 513 and $519 \mathrm{eV}$. With increasing exposures both intensities increased. It is important to mention that on clean, boron-free surface one strong peak appeared at $519 \mathrm{eV}$ besides some loss features at low-energy side of the spectra. We
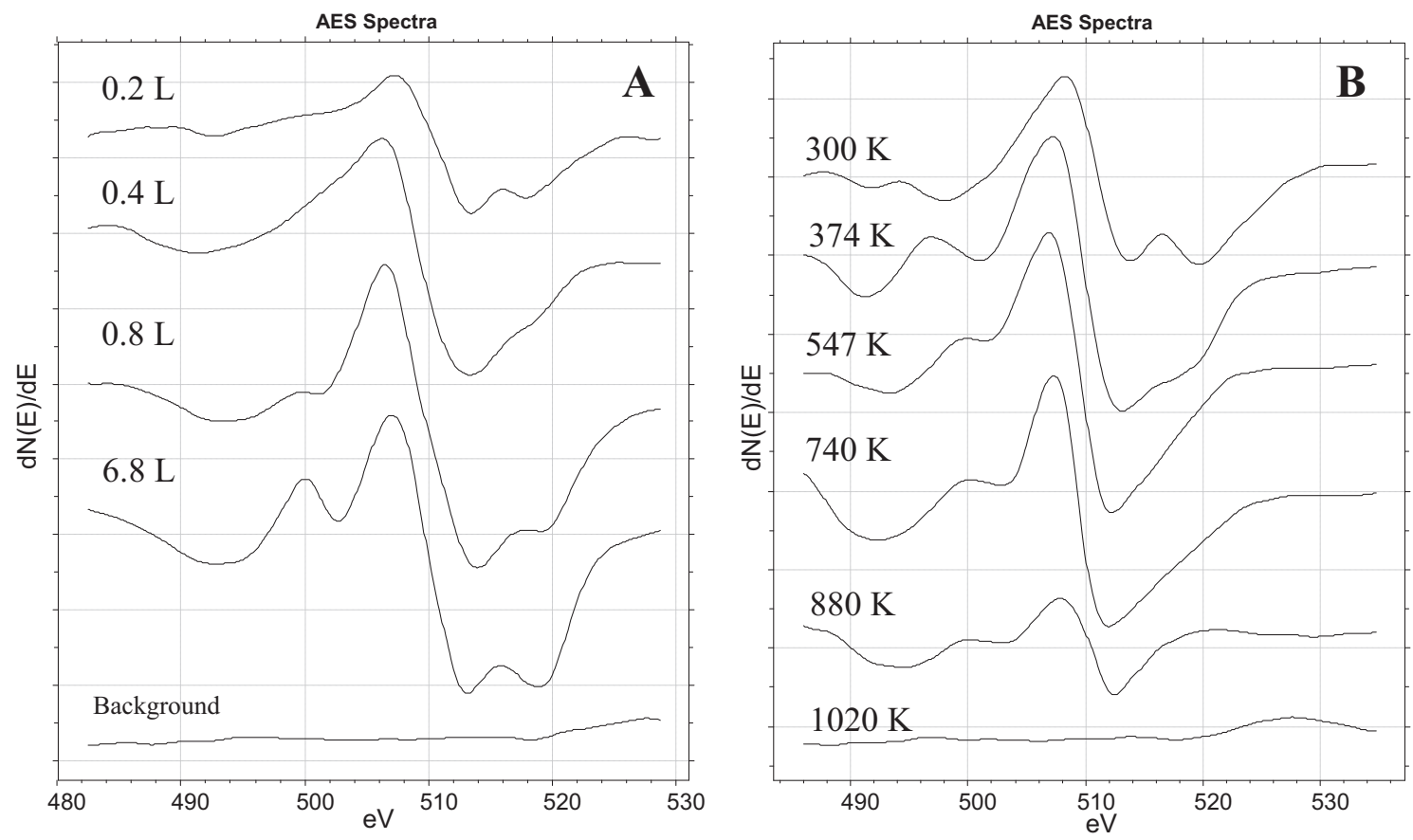

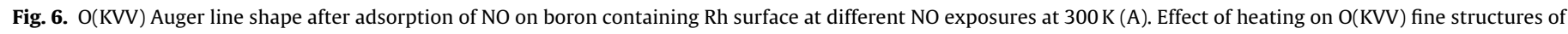
NO saturated boron containing Rh surfaces (B). The intensities are divided by the factor of 2 . 

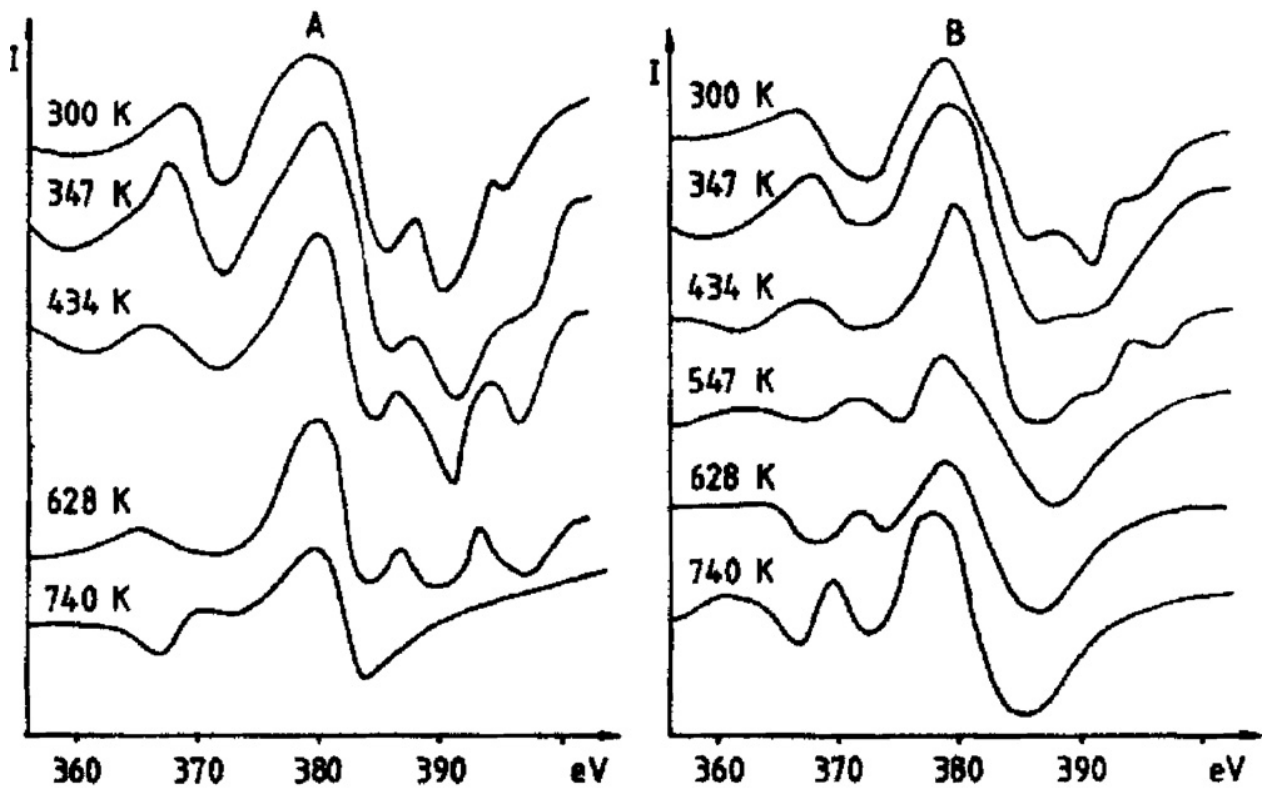

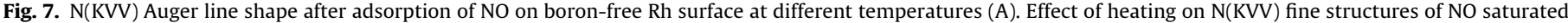
boron containing Rh surfaces (B).

believe that the peak at $519 \mathrm{eV}$ belongs to Rh-NO bond while the transition at $513 \mathrm{eV}$ corresponds to the B-NO bond. When the NO covered sample was heated the peak at $519 \mathrm{eV}$ disappeared when the molecular NO desorbed above $374 \mathrm{~K}$. The intensity of other oxygen peak decreased from $740 \mathrm{~K}$, disappeared between 880 and $1020 \mathrm{~K}$ (Fig. 6B). The formation of a B-O bond is also justified by the fine structure of $\mathrm{B}(\mathrm{KVV})$ and $\mathrm{O}(\mathrm{KVV})$ AES signal obtained in the interaction of oxygen with boron containing Rh at $300 \mathrm{~K}$ [32]. The AES transition of adsorbed oxygen on a $\mathrm{B} / \mathrm{Rh}$ surface appeared at $513 \mathrm{eV}$ at low exposure. With increasing of the oxygen coverage, the intensity of this peak increased and a transition at $518 \mathrm{eV}$ for adsorbed oxygen on Rh sites also developed.

The Auger fine structure of nitrogen after adsorption and decomposition of NO on a clean and boron containing Rh surfaces was somewhat more complex. The adsorbed nitrogen gives a very intense "four-peak" structure in AES $[43,44]$. This strong structure overlaps with that of other $\mathrm{N}$-containing molecules. On clean $\mathrm{Rh}$ after NO adsorption at $300 \mathrm{~K}$ four structure fine structure was observed (Fig. 7A). During heating, independently from the NO dissociation this structure remained up to 547-628 K, above this temperature the AES peak at $383 \mathrm{eV}$ gained, above $740 \mathrm{~K}$, where the boron segregation start to be dominant, practically one peak remained at $383 \mathrm{eV}$. One part of nitrogen desorbs from $\mathrm{Rh}$ atoms, other part of nitrogen migrates from Rh sites to boron, which starts to segregate from $550 \mathrm{~K}$. The formed B-N species exhibits mainly one peak between 380 and $400 \mathrm{eV}$ in Auger spectrum. Similar structure was reported for hexagonal phase of boron nitride and $\mathrm{BN}$ in graphitized steel sheet $[45,46]$. On boron containing surface $\left(R_{B}=0.075\right)$ at saturated NO coverage the four peak structure is present at $300 \mathrm{~K}$. When the molecular NO desorbs at $434 \mathrm{~K}$ and above the AES peak at $384-386 \mathrm{eV}$ was only present with some satellites at lower binding side (Fig. 7B). This peak remained with same intensity up to $1270 \mathrm{~K}$, indicating that BN stable surface compound.

Fig. 8 shows the Auger transitions in boron range from 150 to $200 \mathrm{eV}$. Without boron (so-called clean surface, $R_{B} \approx 0.003$ ) this regime contains some week transitions, which are always present in every AES spectra of Rh. When the surface was flashed to $1050 \mathrm{~K}$, boron signal appeared at $179-183 \mathrm{eV}$. When NO was added to surface at $300 \mathrm{~K}$, the intensity of elemental boron signal significantly decreased, a shoulder at $172 \mathrm{eV}$ gained remarkably. When the surface was heated to higher temperature this peak increased further. In addition, the oxygen Auger feature was shifted from 520 to $513.7 \mathrm{eV}$. The same changes were observed when oxygen was added to the boron-containing surface, and following the oxidation of boron forming $\mathrm{B}_{2} \mathrm{O}_{3}[47,48]$. No doubt

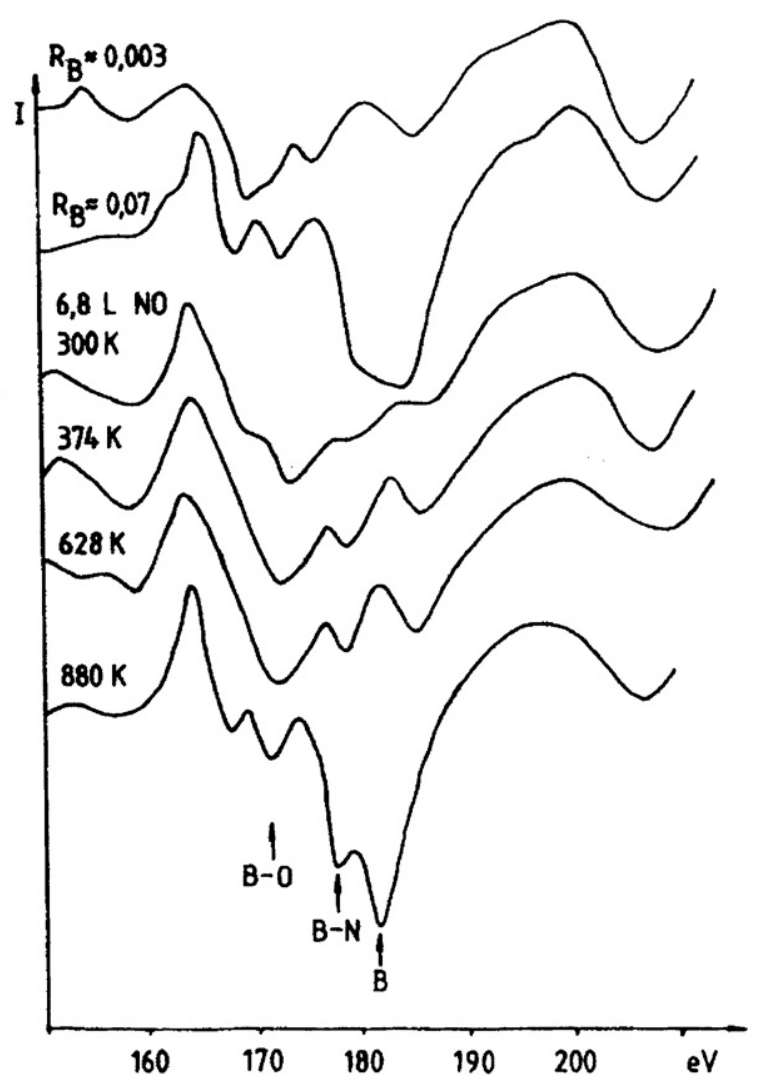

Fig. 8. Effect of heating on $\mathrm{B}(\mathrm{KVV})$ Auger fine structures of NO saturated boron containing Rh surfaces. 
the AES transition at $172 \mathrm{eV}$ belongs to the boron oxide, which can be eliminated above $880 \mathrm{~K}$. A new AES feature developed at $176 \mathrm{eV}$ from $300 \mathrm{~K}$. In harmony with the literature data $[46,49]$, we attributed it to the B-N bond. Similarly to the corresponding N AES signal, it cannot be eliminated below $1270 \mathrm{~K}$. An extensive argon ion bombardment was used to get back the clean surface.

Analysing the UPS, XPS and AES data it turned out that during heat treatment the boron oxide disappeared from the surface above $800 \mathrm{~K}$. Further processes are indicated by the decrease in the $\mathrm{O}$ Auger signal above $850 \mathrm{~K}$ and by the reappearance of the elemental boron feature at $187.8 \mathrm{eV}$ in XPS (Fig. 2). After oxygen adsorption at $300 \mathrm{~K}$ the $\mathrm{B} 1 \mathrm{~s}$ photoemission peak moved to $191.5 \mathrm{eV}$. During heating a shoulder developed at $192.4 \mathrm{eV}$. These binding energies were observed when $\mathrm{B}_{2} \mathrm{O}_{3}$ was treated in reducing atmosphere, where transiently two-valence boron was observed [50]. When the oxygen covered Rh surface was heated above $850 \mathrm{~K}$ the peak shifted back to $187.8 \mathrm{eV}$. As we do not expect the decomposition of the stable $\mathrm{B}_{2} \mathrm{O}_{3}$ species (the dissociation energy of BO molecule is $787 \mathrm{~kJ} / \mathrm{mol}$ [51] and $\mathrm{B}-\mathrm{O}$ single bond dissociation energy is considered to be lower, around $540 \mathrm{~kJ} / \mathrm{mol}$ ), we assume a further segregation of boron and a reaction between $\mathrm{B}_{2} \mathrm{O}_{3}$ and elemental boron

$\mathrm{B}_{(\mathrm{S})}+\mathrm{B}_{2} \mathrm{O}_{3(\mathrm{~S})}-\mathrm{B}_{2} \mathrm{O}_{2(\mathrm{~g})}+\mathrm{BO}_{(\mathrm{g})}$,

the heat of reaction is $141.1 \mathrm{~kJ} / \mathrm{mol}$ [51]. The occurrence of this reaction in the present case is supported by the observation that upon heating the $\mathrm{Rh}$ foil containing the $\mathrm{B}-\mathrm{O}$ complex to high temperature we detected desorbing species at 54 and $27 \mathrm{amu}\left(\mathrm{B}_{2} \mathrm{O}_{2}\right.$ and $\mathrm{BO}$, respectively); the peak temperature was $1050 \mathrm{~K}$. Note that partial oxidation of bulk boron leads to the formation of $(\mathrm{BO})_{\mathrm{x}}$ which vaporizes at $1300 \mathrm{~K}$, as $\mathrm{B}_{2} \mathrm{O}_{2}$, and disproportionates on condensation [52].

In the interaction of NO with boron-containing Rh surface above $900 \mathrm{~K}$ we prepared a clean single BN layer in monolayer or close to monolayer regime. An h-BN layer was found to bind a quite large number of substrates, even when the lattice constant of h-BN and the substrate do not match. The prototypical example is the $\mathrm{h}-\mathrm{BN} / \mathrm{Ni}(111)$ interface, which has nice lattice matching and forms a simple epitaxial $1 \times 1$ structure $[13,53]$. In the case of incommensurate interfaces, the mismatch can lead to some extraordinary structures [54]. Corso et al. [15] have reported the formation of a self-assembled nanostructure, the so-called nanomesh, on the lattice mismatched $\mathrm{Rh}\left(\begin{array}{lll}1 & 1\end{array}\right)$ surface with a periodicity of about $3.2 \mathrm{~nm}$. This corresponds to a situation where the lattice of $12 \times 12 \mathrm{Rh}(111)$ matches $13 \times 13$ h-BN cells forming periodic nanomesh structure, which is caused by the latticemismatch between $\mathrm{Rh}(111)$ and h-BN. Although our Rh sample is polycrystalline we cannot exclude that the formed BN constitute nanomesh on the surface. Since the first discovery of nanomesh [15] on $\mathrm{Rh}(111)$ surface, similar structures have also been found on $\mathrm{Ru}(00001)$ [55], $\operatorname{Pd}\left(\begin{array}{lll}1 & 1 & 1\end{array}\right)$ [56] and $\operatorname{Pd}\left(\begin{array}{lll}1 & 1 & 0\end{array}\right)$ [57].

\section{Conclusions}

The segregation of boron from a Rh foil started at $700 \mathrm{~K}$. The segregated boron produced a peak for the B 1 s level on XPS at $187.8 \mathrm{eV}$ and emission in UPS at $8.6-9.0 \mathrm{eV}$, respectively. The presence of boron drastically altered the surface behavior of $\mathrm{Rh}$; the uptake of NO increased by about 30-37\%. The extent of NO dissociation (at saturation) at highest boron level was almost $98 \%$. This feature strongly suggest a direct interaction between NO and boron on the surface. The presence of boron greatly stabilized the adsorbed oxygen and nitrogen formed during NO dissociation. Boron oxides (BO, $\mathrm{B}_{2} \mathrm{O}_{2}$ ) sublimated from the surface below $1000 \mathrm{~K}$. The stabilizing effect was so great that the nitrogen bonded was not released below $1200 \mathrm{~K}$. The formation of boron nitride was detected at 9.0-9.5 eV in UPS. This photoemission can be attributed to the formation of $\sigma$ bond between $\mathrm{B}$ and $\mathrm{N}$. Above $400 \mathrm{~K}$ new intense Auger transitions developed at $176 \mathrm{eV}(\mathrm{B})$ and $384 \mathrm{eV}(\mathrm{N})$, which are typical for $\mathrm{B}-\mathrm{N}$ species. A clean, single BN layer formed on the surface, presumable in nanomash structure.

\section{Acknowledgement}

The financial support of the Hungarian Scientific Research Fund (OTKA) through projects K81517, K81660 and Támop-4.2.2/B-10/12010-0012 are acknowledged.

\section{References}

[1] Y. Zhang, T.W. Tan, H.L. Stormer, P. Kim, Nature 438 (2005) 201-204.

[2] A. Geim, K. Novoselov, Nature Materials 6 (2007) 183-191.

[3] L. Britnell, R.V. Gorbachev, R. Jalil, B.D. Belle, F. Schedin, M.I. Katsnelson, L. Eares, S.V. Morozov, A.S. Mayorov, N.M.R. Peres, A.H.C. Neto, J. Leist, A.K. Geim, L.A. Ponomarenko, K.S. Novoselov, Nano Letters 12 (2012) 1707-1710.

[4] C.R. Dean, A.F. Young, I. Meric, C. Lee, L. Wang, S. Sorgenfrei, K. Watanabe, T. Taniguchi, P. Kim, K.L. Shepard, J. Hone, Nature Nanotechnology 5 (2010) $722-726$.

[5] M. Xie, J. Wang, Y.K. Yap, Journal of Physical Chemistry C 114 (2010) $16236-16241$.

[6] Z. Liu, L. Song, S. Zhao, I. Huang, L. Ma, J. Zhang, J. Lou, P.M. Ajayan, Nano Letters 11 (2011) 2032-2037.

[7] R.M. Ribeiro, N.M.R. Peres, Physical Review B 83 (2011), No. 235312.

[8] W.-Q. Han, L. Wu, Y. Zhu, K. Watanabe, T. Taniguchi, Applied Physics Letters 93 (2008) 223103-223106.

[9] J.C. Meyer, A. Chuvilin, G. Algara-Siller, J. Biskupek, U. Kaiser, Nano Letters 9 (2009) 2683-2689.

[10] J.H. Warner, M.H. Rümmeli, A. Bachmatiuk, B. Büchner, ACS Nano 4 (2010) 1299-1304.

[11] C. Lee, Q. Li, W. Kalb, X. Liu, H. Berger, R.W. Carpick, J. Hona, Science 328 (2010) 76-80.

[12] J. Jones, M. Trenary, Journal of Physical Chemistry C 112 (2008) 20443-20450.

[13] B. Grad, P. Blaha, K. Schwarz, W. Auwarter, T. Greber, Physical Review B 68 (2003), No. 085404

[14] A.B. Preobrajenski, A.S. Vinigradov, N. Martensson, Surface Science 582 (2005) 21-30.

[15] M. Corso, W. Auwarter, M. Muntwiler, A. Tamai, T. Greber, J. Osterwalder, Science 303 (2004) 217-220.

[16] J. Kiss, F. Solymosi, Surface Science 135 (1983) 243-260.

[17] J. Kiss, F. Solymosi, Surface Science 177 (1986) 191-206.

[18] F. Solymosi, L. Bugyi, Applied Surface Science 21 (1985) 125-138.

[19] F. Solymosi, J. Kiss, Chemical Physics Letters 110 (1984) 639-642.

[20] F. Solymosi, J. Kiss, Surface Science 149 (1985) 17-32.

[21] D.G. Castner, G.A. Somorjai, Surface Science 83 (1979) 60-82.

[22] S. Semancik, G.L. Haller, J.T. Yates Jr., Applied Surface Science 10 (1982) 546-558.

[23] R.E. Hendershot, R.S. Hansen, Journal of Catalysis 98 (1986) 150-165

[24] L. Bugyi, J. Kiss, F. Solymosi, Journal of Vacuum Science and Technology A 5 (1987) 863-864.

[25] R.J. Baird, R.C. Ku, P. Wynblatt, Surface Science 97 (1980) 346-362.

[26] C.T. Campbell, J.M. White, Applied Surface Science 1 (1978) 347-359.

[27] H.A.C.M. Hendrickx, B.E. Nieuwenhuys, Surface Science 175 (1986) 185-196.

[28] T.W. Root, L.D. Schmidt, G.B. Fisher, Surface Science 150 (1985) 173-192.

[29] L.A. DeLouise, N. Winograd, Surface Science 159 (1985) 199-213.

[30] L. Bugyi, J. Kiss, K. Révész, F. Solymosi, Surface Science 233 (1990) 1-11.

[31] F. Bondino, G. Comelli, A. Baraldi, Journal of Chemical Physics 119 (2003) $12525-12533$.

[32] J. Kiss, K. Révész, F. Solymosi, Applied Surface Science 37 (1989) 95-110.

[33] J.H. Scofield, Journal of Electron Spectroscopy 8 (1976) 129-137.

[34] C.T. Campbell, S.-K. Shi, J.M. White, Applied Surface Science 2 (1979) 382-396.

[35] T.B. Fryberger, J.L. Gland, P.C. Stair, Langmuir 3 (1987) 1015-1025.

[36] D.J. Joyner, R.F. Willis, Philosophical Magazine A 43 (1981) 815-833.

[37] T.B. Fryberger, J.L. Gland, P.C. Stair, Journal of Vacuum Science and Technology A 5 (1987) 858-862.

[38] E. Umbach, S. Kulkarni, P. Feulner, D. Menzel, Surface Science 88 (1979) 65-94.

[39] M. Kiskinova, G. Pirug, H.P. Bonzel, Surface Science 136 (1984) 285-295.

[40] D.E. Ibbotson, T.S. Wittrig, W.H. Weinberg, Surface Science 110 (1981) 294-312.

[41] H. Conrad, G. Ertl, J. Küppers, E.E. Latta, Surface Science 65 (1977) 235-244.

[42] W. von Niessen, Theoretica Chimica Acta 29 (1973) 29-48.

[43] J.C. Fuggle, D. Menzel, Proc. 7th Intern. Vac. Congr., Vienna, 1977, p. 1003.

[44] F. Solymosi, J. Kiss, Surface Science 104 (1981) 181-198.

[45] S.J. Simko, M.C. Militello, Surface Science Spectra 1 (1992) 288-291.

[46] T. Mega, R. Morimoto, M. Morita, J. Shimomura, Surface and Interface Analysis 24 (1996) 375-379.

[47] D.J. Joyner, D.M. Hercules, Journal of Chemical Physics 72 (1980) 1095-1108

[48] J.W. Rogers Jr., M.L. Knotek, Applied Surface Science 13 (1982) 352-366.

[49] G. Hanke, K. Müller, Surface Science 152 (1985) 902-910. 
[50] I. Bertóti, R. Kelly, M. Mohai, A. Tóth, Nuclear Instruments and Methods B 80-81 (1993) 1219-1225.

[51] B.deB. Darwent, Bond Dissociation Energies in Simple Molecule, National Bureau of Standards, Washington, D.C., 1970.

[52] M.G. Ingram, R.F. Porter, W.A. Chupka, Journal of Chemical Physics 25 (1956) 498-501.

[53] M.N. Huda, L. Kleinman, Physical Review B 74 (2006), No. 075418.
[54] H.-P. Koch, R. Laskowski, P. Blaha, K. Schwarz, Physical Review B 84 (2011), No. 245410.

[55] A. Goriachko, Y. He, M. Knapp, H. Over, Langmuir 23 (2007) 2928-2931.

[56] M. Morscher, M. Corso, T. Greber, J. Osterwalder, Surface Science 600 (2007) 3280-3284.

[57] M. Corso, T. Greber, J. Osterwalder, Surface Science 577 (2005) L78-L84. 